\title{
COVID-19 and Venous Thromboembolism: A Meta-analysis of Literature Studies
}

\author{
Alessandro Di Minno, PharmD, $\mathrm{PhD}^{1}$ Pasquale Ambrosino, MD, $\mathrm{PhD}^{2} \quad$ Ilenia Calcaterra, $\mathrm{MD}^{3}$ \\ Matteo Nicola Dario Di Minno, MD, PhD 4
}

${ }^{1}$ Department of Pharmacy, Federico II University, Naples, Italy

${ }^{2}$ Istituti Clinici Scientifici Maugeri IRCCS, Pavia, Italy

${ }^{3}$ Department of Clinical Medicine and Surgery, Federico II University,

Naples, Italy

${ }^{4}$ Department of Translational Medical Sciences, Federico II University,

Naples, Italy

Semin Thromb Hemost 2020;46:763-771.

\begin{abstract}
Address for correspondence Pasquale Ambrosino, MD, PhD, Istituti Clinici Scientifici Maugeri IRCCS, Via Salvatore Maugeri 4, 27100 Pavia, Italy (e-mail: pasquale.ambrosino@icsmaugeri.it).
\end{abstract}

\begin{abstract}
Keywords

- SARS-CoV-2

- COVID-19

- thrombosis

- disability

- anticoagulants.

Coronavirus disease 2019 (COVID-19) may have a wide spectrum of clinical presentations, leading in some cases to a critical condition with poor long-term outcomes and residual disability requiring post-acute rehabilitation. A major concern in severe COVID19 is represented by a concomitant prothrombotic state. However, contrasting data are available about the prevalence of venous thromboembolism (VTE), including deep vein thrombosis (DVT) and/or pulmonary embolism (PE). A detailed search on the association of COVID-19 with thromboembolic complications was conducted in the main electronic databases (PubMed, Web of Science, and Scopus) according to the Preferred Reporting Items for Systematic Reviews and Meta-Analyses (PRISMA) guidelines. The weighted mean prevalence (WMP) with $95 \%$ confidence interval $(95 \% \mathrm{Cl})$ was calculated with the random-effects model. Twenty studies enrolling 1,988 COVID-19 patients were included. The WMP of VTE was 31.3\% (95\% Cl: 24.3-39.2\%). The WMP of DVT was $19.8 \%$ (95\% Cl: $10.5-34.0 \%$ ), whereas the WMP of PE was $18.9 \%$ (95\% Cl: $14.4-24.3 \%$ ). Similar results were obtained when specifically analyzing studies on patients admitted to intensive care units and those on patients under antithrombotic prophylaxis. Regression models showed that an increasing age was associated with a higher prevalence of VTE (Z-score: 3.11, $p=0.001$ ), DVT (Z-score: $2.33, p=0.002$ ), and PE (Z-score: $3.03, p=0.002$ ), while an increasing body mass index was associated with an increasing prevalence of PE (Z-score $=2.01, p=0.04)$. Male sex did not impact the evaluated outcomes. The rate of thromboembolic complications in COVID-19 patients is definitely high. Considering the risk of fatal and disabling complications, adequate screening procedures and antithrombotic strategies should be implemented.
\end{abstract}

In December 2019, the novel severe acute respiratory syndrome coronavirus 2 (SARS-CoV-2) appeared in Wuhan, China. ${ }^{1}$ Despite the attempts to minimize exportation, SARS-CoV-2 showed an international spread, thus becoming a public health emergency. ${ }^{2}$ Therefore, in March 2020, the
World Health Organization (WHO) declared the novel coronavirus outbreak pandemic. ${ }^{3}$

The rapidly increasing number of studies on SARS-CoV-2 infection indicates that this viral agent can cause coronavirus disease 2019 (COVID-19), a syndrome with a wide spectrum published online September 3, 2020
Issue Theme Maintaining Hemostasis and Preventing Thrombosis in COVID-19 -Part I; Guest Editors: Emmanuel J. Favaloro, PhD, FFSc (RCPA), and Giuseppi Lippi, MD.
Copyright $\odot 2020$ by Thieme Medical Publishers, Inc., 333 Seventh Avenue, New York, NY 10001, USA. Tel: +1(212) 760-0888.
DOI https://doi.org/ $10.1055 / \mathrm{s}-0040-1715456$. ISSN 0094-6176. 
of clinical presentations. ${ }^{4,5}$ COVID-19 may range from a mild disease with flulike symptoms to a critical care respiratory condition requiring specialized management at intensive care units (ICUs), ${ }^{6-8}$ with poor long-term outcomes and residual chronic disability. ${ }^{9,10}$

Besides the respiratory manifestations with severe disabling complications, another major concern is represented by evidence of consistent hemostatic changes in patients with severe or critical COVID-19, likely related to a prothrombotic switch. ${ }^{11,12}$

Among COVID-19 patients, it is reasonable to assume that those with a very severe disease could exhibit high risk of venous thromboembolism (VTE), including deep vein thrombosis (DVT) and/or pulmonary embolism (PE). Critically ill patients with COVID-19 are bedridden in ICU because of acute infective disease determining respiratory failure, thus resulting in a high VTE risk, as predicted by a Padua score (bedridden: 3 points; infection: 1 point; respiratory failure: 1 point). ${ }^{13}$ Contrasting data are currently available about the prevalence of thromboembolic events in COVID-19 patients.

The aim of the present study was to perform a systematic literature search with meta-analysis of studies reporting the prevalence of VTE, DVT, or PE in patients with COVID-19. Moreover, we implemented some meta-regression models to evaluate the effect of demographic and clinical variables on the evaluated outcomes.

\section{Materials and Methods}

We developed a protocol for this systematic review, defining the search strategy, the outcomes, the inclusion and exclusion criteria, the approach for quality assessment, and the statistical methods.

\section{Search Strategy and Selection Criteria}

To detect all available studies on the association of COVID-19 with thromboembolic complications, we conducted a systematic literature search in PubMed, Web of Science, and Scopus according to the Preferred Reporting Items for Systematic Reviews and Meta-Analyses (PRISMA) guidelines. ${ }^{14}$ The last search was performed on May 19, 2020, with no language restriction, by using the following terms in all possible combinations: COVID-19, SARS-CoV-2, VTE, DVT, PE, vein, venous, thrombosis, thrombosis thrombotic, thromboembolism, pulmonary, embolism, embolic, and occlusion. Moreover, the lists of the bibliographic references of all included articles were manually screened. In case of missing data among studies fulfilling the inclusion criteria, the authors were contacted by e-mail to try to claim the original data. Two authors (A.D.M. and P.A.) analyzed each article and separately performed the extraction of data. In case of disagreement, a third investigator was consulted (M.N.D.D.M.). Discrepancies were resolved by consensus. Overall, selection results showed a high interreader agreement $(\kappa=1.00)$ and were reported according to PRISMA flow-chart (-Fig. 1 ).

According to a predetermined protocol, all studies reporting data about the association of COVID-19 with thromboembolic complications were included. Reviews and articles on animal models were excluded. Overall, we included in the analysis all studies providing data about the prevalence of VTE, DVT, or PE among COVID-19 patients, with VTE being defined as the presence of any thromboembolic complication (DVT, PE, or a combination of both). ${ }^{15}$ Studies reporting on the autopsy evidence of thromboembolic events were also included. Superficial vein thrombosis was not considered as VTE episode and was excluded from the analysis. In each study, data regarding sample size, mean age of enrolled patients, percentage of male patients, and body mass index (BMI) were extracted. Formal quality score adjudication was not used since most included studies were small cohort studies.

\section{Data Synthesis and Statistics}

Data synthesis and analyses were performed by using comprehensive meta-analysis (version 2; Biostat). The prevalence of VTE, DVT, and of PE was expressed as weighted mean prevalence (WMP) with 95\% confidence intervals (95\% CIs). The pooled effect was tested by means of Z-scores, with $p<0.05$ being considered statically significant. We evaluated statistical heterogeneity among studies with chi-squared Cochran's Q-test and with $I^{2}$ index, which measures the inconsistency among results of studies and defines the proportion of total variation in study estimates that is due to heterogeneity rather than sampling error. In particular, an $I^{2}$ value of $25 \%$ corresponds to low, 25 to $50 \%$ to moderate, and $50 \%$ to high heterogeneity. ${ }^{16}$ Funnel plots of the logit event rate versus the standard error were used as a graphical representation of publication bias. To detect a potential small-study effect, funnel plots were visually inspected for asymmetry. Moreover, the Egger test was used to assess publication bias over and above any subjective evaluation, with $p<0.10$ being considered statistically significant. ${ }^{17}$ To be as conservative as possible, the random-effects method was used to take into account the variability among included studies.

\section{Subgroup Analyses}

We performed separate subgroup analyses on (1) studies specifically including ICU patients; (2) studies specifically including patients receiving antithrombotic prophylaxis; and (3) studies systematically performing VTE screening.

\section{Meta-regression Analyses}

We hypothesized that mean age of the study population, the percentage of males, and BMI may affect the rate of thromboembolic complications observed in different studies. Thus, we planned to perform meta-regression analyses after implementing regression models with the prevalence of VTE, DVT, and PE as dependent variables $(y)$ and the aforementioned covariates as independent variables $(x)$. Comprehensive meta-analysis software (version 2, Biostat) was used for the multivariate approach.

\section{Results}

After excluding duplicates, the search detected 222 articles. Of these, 140 were excluded because they were off the topic (after scanning the title and/or the abstract), and another 40 


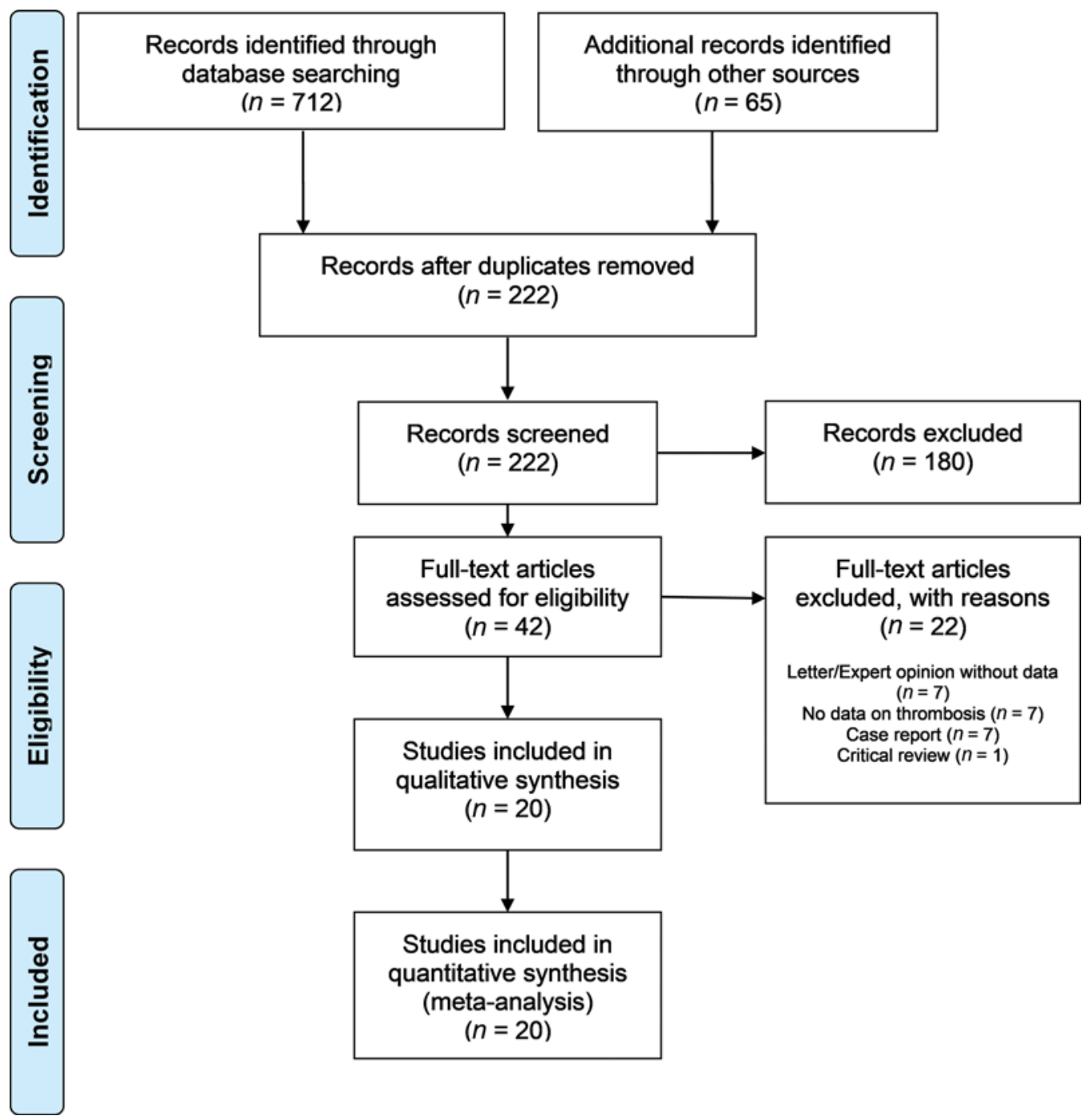

Fig. 1 Preferred Reporting Items for Systematic Reviews and Meta-Analyses (PRISMA) flow diagram.

because they were reviews/commentaries or lacked of data of interest. Another 22 studies were excluded after fulllength paper evaluation (-Fig. 1). Studies by Lodigiani et $\mathrm{al}^{18}$ and Middeldorp et $\mathrm{al}^{19}$ provided separate data for ICU patients and general ward patients. The two populations were analyzed as separate datasets.

A total of 20 studies (22 datasets) ${ }^{18-37}$ enrolling 1,988 COVID-19 patients were finally included in the meta-analysis.

\section{Study Characteristics}

Major characteristics of included studies are shown in -Table 1. The number of patients varied from 11 to 328 , with mean age of 64.3 years (from 51.7 to 80.5 years). Eleven studies $^{18,19,21,24,25,28,30,32-34,36}$ specifically enrolled patients admitted to ICU. A total of $66.8 \%$ of patients were males (range: $45.7-90.9 \%$ ) and the mean BMI was $28.2 \mathrm{~kg} / \mathrm{m}^{2}$ (range: $\left.23.6-31.3 \mathrm{~kg} / \mathrm{m}^{2}\right)$. Antithrombotic prophylaxis was used by $78.4 \%$ of patients (range: $0-100 \%$ ).

\section{Prevalence of Thromboembolic Complications}

The WMP of VTE in the 1,988 COVID-19 patients was 31.3\% (95\% CI: $24.3-39.2 \%$, - Fig. 2). ${ }^{18-37}$ The heterogeneity among studies was significant $\left(I^{2}: 89.2 \%, p<0.001\right)$ and was not reduced by the exclusion of one study at time. Results were similar when specifically analyzing studies on ICU patients (WMP: 32.7\%, 95\% CI: 21.9-45.7\%; $I^{2}$ : 89.9\%, $p<0.001)^{18,19,21,24,25,28,30,32-34,36}$ When analyzing studies specifically enrolling patients receiving antithrombotic prophylaxis, the WMP of VTE was $23.9 \%$ (95\% CI: $15.9-34.4 \%$; $I^{2}$ : $87.8 \%, p<0.001) .{ }^{18-20,24,25,28,30,33,34}$ The WMP of VTE was $37.1 \%$ (95\% CI: $19.0-59.8 \%$ ) for studies systematically performing thrombosis screening in all enrolled patients, and 29.4\% (95\% CI: $22.5-37.4 \%$ ) for those performing imaging tests in symptomatic patients ( - Table 2 ).

Twelve studies (13 datasets) $)^{19,21,22,24,25,28-30,32,33,35,37}$ showed that the WMP of DVT among 1,157 COVID-19 patients was $19.8 \%$ (95\% CI: $10.5-34.0 \%$; $I^{2}$ : $93.3 \%$, $p<0.001$ ) (-Fig. 2). Similar results were obtained specifically analyzing studies on ICU patients (WMP: $17.9 \%, 95 \% \mathrm{CI}$ : $\left.6.6-40.5 \% ; I^{2}: 94.0 \%, p=0.346\right)$. A lower rate of DVT was found when considering studies on patients receiving antithrombotic prophylaxis (WMP: $8.0 \%, 95 \% \mathrm{CI}: 2.3-2.4 \%$; $I^{2}$ : $92.7 \%, p<0.001$ ). A higher WMP of DVT was found in studies systematically screening all enrolled patients ( - Table 2 ). 
Table 1 Characteristics of included studies

\begin{tabular}{|c|c|c|c|c|c|c|}
\hline Study & $\begin{array}{l}\text { Patients } \\
\text { (n) }\end{array}$ & $\begin{array}{l}\text { Age } \\
\text { (y) }\end{array}$ & $\begin{array}{l}\text { Males } \\
(\%)\end{array}$ & $\begin{array}{l}\text { BMI } \\
\left(\mathrm{kg} / \mathrm{m}^{2}\right)\end{array}$ & $\begin{array}{l}\text { ICU patient } \\
\text { (\%) }\end{array}$ & $\begin{array}{l}\text { Anticoagulation } \\
\text { (\%) }\end{array}$ \\
\hline Bompard et al, $2020^{20}$ & 135 & 64.7 & 70.0 & - & 18.0 & 100 \\
\hline Cui et al, $2020^{21}$ & 81 & 59.9 & 45.7 & - & 100 & 0 \\
\hline Demelo-Rodríguez et al, $2020^{22}$ & 156 & 68.1 & 65.4 & 26.9 & 11.5 & 98.0 \\
\hline Grillet et al, $2020^{23}$ & 100 & 66.0 & 70.0 & - & 39.0 & - \\
\hline Helms et al, $2020^{24}$ & 150 & 62.3 & 81.3 & - & 100 & 100 \\
\hline Klok et al, $2020^{25}$ & 184 & 64.0 & 76.0 & - & 100 & 100 \\
\hline Lax et al, $2020^{26}$ & 11 & 80.5 & 72.7 & - & - & 91.0 \\
\hline Leonard-Lorant et al, $2020^{27}$ & 106 & 64.0 & 66.0 & 27.0 & 45.2 & 39.6 \\
\hline Llitjos et al, $2020^{28}$ & 26 & 68.0 & 77.0 & 30.0 & 100 & 100 \\
\hline 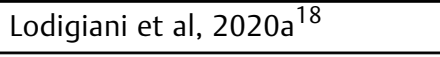 & 18 & - & - & - & 100 & 100 \\
\hline Lodigiani et al, $2020 b^{18}$ & 26 & - & - & - & 0 & - \\
\hline Marone and Rinaldi, $2020^{29}$ & 30 & - & - & - & 0 & - \\
\hline Middeldorp et al, 2020a ${ }^{19}$ & 75 & 62.0 & 77.0 & 27.0 & 100 & 100 \\
\hline Middeldorp et al, 2020b ${ }^{19}$ & 123 & 60.0 & 59.0 & 28.0 & 0 & 100 \\
\hline Poissy et al, $2020^{30}$ & 107 & 57.0 & 59.1 & 29.0 & 100 & 100 \\
\hline Poyiadi et al, $2020^{31}$ & 328 & 61.3 & 45.9 & - & 25.3 & 37.2 \\
\hline Ren et al, $2020^{32}$ & 48 & 70.7 & 54.2 & - & 100 & 98 \\
\hline Spiezia et al, $2020^{33}$ & 22 & 67.0 & 90.9 & 30.0 & 100 & 100 \\
\hline Thomas et al, $2020^{34}$ & 63 & 59.0 & 69.0 & - & 100 & 100 \\
\hline Wichmann et al, $2020^{35}$ & 12 & 73.0 & 75.0 & 28.7 & 41.7 & 33.3 \\
\hline Wright et al, $2020^{36}$ & 44 & 51.7 & 63.6 & 31.3 & 100 & 54.5 \\
\hline Zhang et al, $2020^{37}$ & 143 & 63.0 & 51.7 & 23.6 & 10.5 & 37.1 \\
\hline
\end{tabular}

Abbreviations: BMI, body mass index; ICU, intensive care unit; $n$, number; y, years.

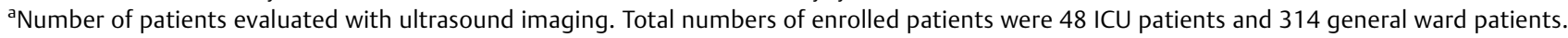

Fourteen studies ( 16 datasets) ${ }^{18-20,23-25,27,28,30,31,34,35,37}$ showed that the WMP of PE among 1,593 COVID-19 patients was $18.9 \%$ (95\% CI: $14.4-24.3 \% ; I^{2}: 76.3 \%, p<0.001$ ) (-Fig. 2). Similar results were obtained specifically analyzing studies on ICU patients (WMP: 16.1\%, 95\% CI: 13.1-19.6\%; $I^{2}$ : 13.0\%, $p=0.330)^{18,19,24,25,28,30,34}$ and studies on patients receiving antithrombotic prophylaxis (WMP: $15.4 \%, 95 \% \mathrm{CI}: 11.2-$ 20.8\%; $I^{2}: 66.6 \%, p=0.002 .{ }^{18-20,24,25,28,30,34}$ Moreover, no difference in PE rate was observed between studies systematically performing thrombosis screening in all enrolled patients and those performing imaging tests in symptomatic patients (-Table 2).

\section{Publication Bias}

Funnel plot examination ( $\mathbf{- F i g . ~ 3 ) ~ s u g g e s t e d ~ t h e ~ a b s e n c e ~ o f ~}$ publication bias and of small-study effect, confirmed by the Egger test for studies reporting on the prevalence of VTE $(p=0.621)$, DVT $(p=0.136)$, and PE $(p=0.314)$ in COVID-19 patients.

\section{Meta-regression Analyses}

Regression models (-Fig. 4) showed that an increasing age was associated with a higher prevalence of VTE (Z-score: 3.11, $p=0.001$ ), DVT (Z-score: $2.33, p=0.002)$, and PE (Z- score: 3.03, $p=0.002$ ) in COVID-19 patients. In addition, an increasing BMI was associated with an increasing prevalence of PE (Z-score: $2.01, p=0.04$ ), but not of VTE (Z-score: -0.20 , $p=0.843$ ) or DVT (Z-score: $-0.65, p=0.517$ ). The rate of VTE, DVT, or PE in COVID-19 patients was not impacted by the prevalence of male sex (Z-score: 0.009, $p=0.999$; Z-score: $-0.99, p=0.321$; and Z-score: $1.03, p=0.304$, respectively).

\section{Discussion}

Results of the present meta-analysis consistently show that COVID-19 can be associated with thromboembolic complications. In particular, we found that the prevalence of VTE is $\approx 30 \%$ in COVID-19 patients, with DVT being reported for $\approx 20 \%$ and with PE being reported for $\approx 18 \%$ of patients. Regression models showed that an increasing age is associated with a higher prevalence of VTE, DVT, or PE, while an increasing BMI is associated with an increasing prevalence of PE. No impact of male sex on the evaluated outcomes was found.

To the best of our knowledge, this is the first meta-analysis summarizing the growing amount of literature data on the prevalence of thromboembolic events in patients with COVID19 , a respiratory transmitted virus that in 6 months afflicted more than 7 million people and killed more than 400,000 
Venous Thromboembolism
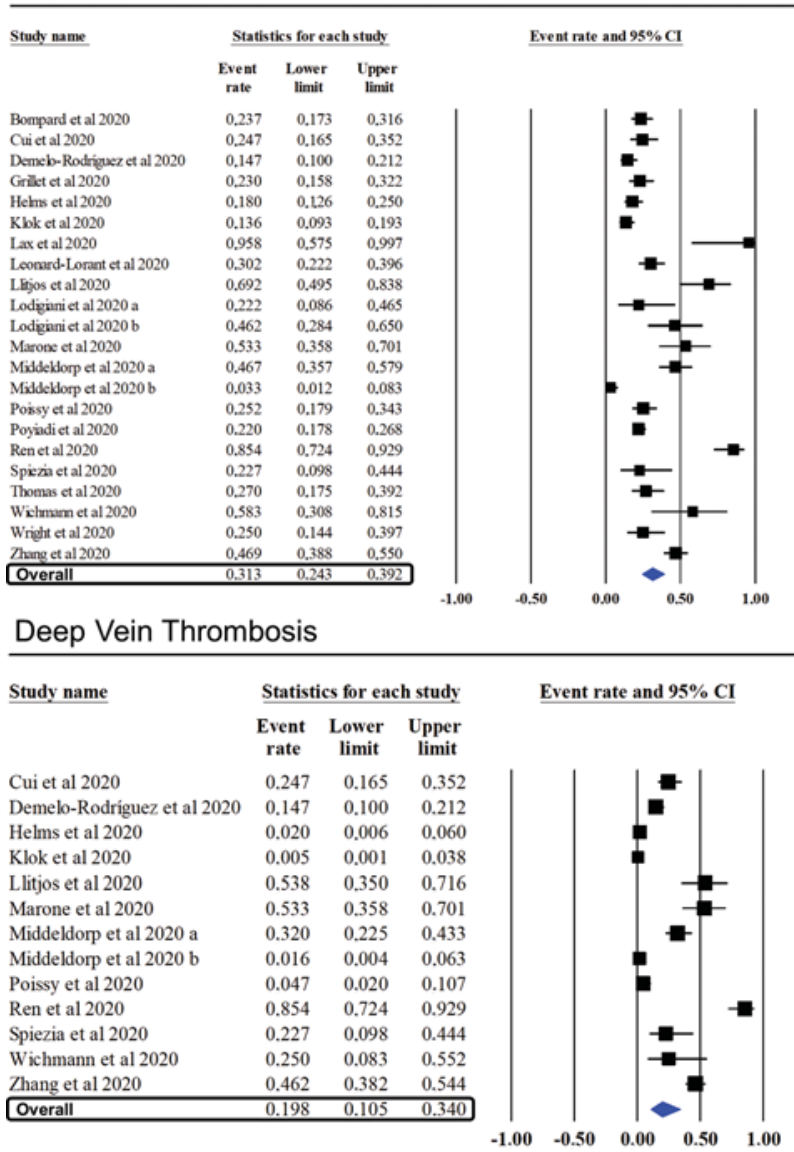

Pulmonary Embolism

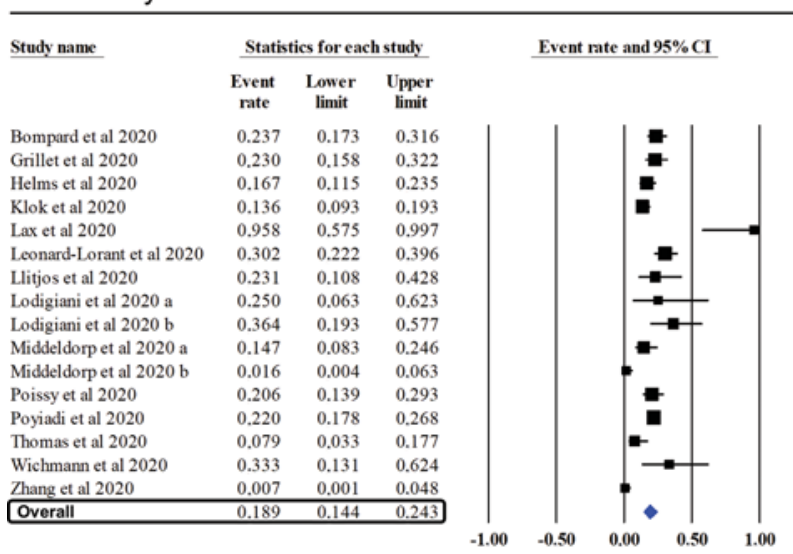

Fig. 2 Prevalence of venous thromboembolism, deep vein thrombosis, and pulmonary embolism in COVID-19 patients.

people worldwide. Besides the respiratory syndrome with severe disabling complications, the hypercoagulable state in COVID-19 patients may lead to a high thrombotic risk with dramatic impact on prognosis and mortality. ${ }^{35}$

It is plausible that the severity of COVID-19 infection could be an important determinant in the onset of VTE as critically ill patients are bedridden in ICU due to an acute infective disease determining respiratory failure, with a Padua prediction score always $>5 .^{13}$ In keeping with this, it should be considered that obesity and an older age, which may further increase the VTE risk and the final Padua score, are potential risk factors for
Table 2 Subgroup analyses

\begin{tabular}{|c|c|c|c|}
\hline & $\begin{array}{l}\text { No. of } \\
\text { studies }\end{array}$ & $\begin{array}{l}\text { No. of } \\
\text { patients }\end{array}$ & $\begin{array}{l}\text { Effect size } \\
\text { WMP }[95 \% \mathrm{Cl}]\end{array}$ \\
\hline \multicolumn{3}{|l|}{ VTE } & Panel A \\
\hline $\begin{array}{l}\text { No } \\
\text { screening }\end{array}$ & $\begin{array}{l}15 \\
\text { (17 datasets) }\end{array}$ & 1,460 & $\begin{array}{l}\text { WMP: } 29.4 \% \\
\text { [22.5\%, 37.4\%] } \\
\quad P^{2}=85.3 \% \\
p<0.0001\end{array}$ \\
\hline Screening & $\begin{array}{l}5 \\
\text { (5 datasets) }\end{array}$ & 528 & $\begin{array}{l}\text { WMP: } 37.1 \% \\
{[19.0 \%, 59.8 \%]} \\
P^{2}=94.8 \% \\
p<0.0001\end{array}$ \\
\hline \multicolumn{3}{|l|}{ DVT } & Panel B \\
\hline $\begin{array}{l}\text { No } \\
\text { screening }\end{array}$ & $\begin{array}{l}8 \\
\text { (9 datasets) }\end{array}$ & 729 & $\begin{array}{l}\text { WMP: } 12.1 \% \\
\text { [4.5\%, } 28.7 \%] \\
\quad P^{2}=97.9 \% \\
p<0.0001\end{array}$ \\
\hline Screening & $\begin{array}{l}4 \\
\text { (4 datasets) }\end{array}$ & 428 & $\begin{array}{l}\text { WMP: } 41.3 \% \\
{[18.1 \%, 69.2 \%]} \\
\quad I^{2}=70.7 \% \\
p<0.0001\end{array}$ \\
\hline \multicolumn{3}{|l|}{ PE } & Panel C \\
\hline $\begin{array}{l}\text { No } \\
\text { screening }\end{array}$ & $\begin{array}{l}12 \\
\text { (14 datasets) }\end{array}$ & 1,350 & $\begin{array}{l}\text { WMP: } 20.5 \% \\
{[18.3 \%, 22.9 \%]} \\
\quad P^{2}=74.0 \% \\
p<0.0001\end{array}$ \\
\hline Screening & $\begin{array}{l}2 \\
\text { (2 datasets) }\end{array}$ & 243 & $\begin{array}{l}\text { WMP: } 19.7 \% \\
{[13.5 \%, 27.8 \%]} \\
\quad I^{2}=92.4 \% \\
p<0.0001\end{array}$ \\
\hline
\end{tabular}

Abbreviations: 95\% Cl, 95\% confidence interval; WMP, weighted mean prevalence.

Note: Venous thromboembolism (VTE), deep vein thrombosis (DVT) and pulmonary embolism (PE) from studies with and without systematic screening of thrombotic episodes.

severe COVID-19. ${ }^{5}$ Accordingly, our regression models showed that an increasing age and BMI were associated with an increased prevalence of thromboembolic events.

However, the relationship between SARS-CoV-2 infection and the hemostatic imbalance of COVID-19 patients seems to be more complex and not fully explained by the presence of traditional VTE risk factors. In keeping with this, Clayton et al reported a $4 \%$ incidence of VTE in patients with pneumonia secondary to respiratory tract infections. ${ }^{38}$ Our results show that, compared with this evidence, the rate of VTE in COVID-19 patients is $\approx 7$ - to 8 -fold higher as compared with other respiratory infections. Accordingly, based on previous metaanalytical data, ${ }^{39}$ the frequency of thromboembolic complications in ICU patients is $\approx 12 \%$. Thus, an indirect comparison with results of our subgroup analysis on ICU suggests that the probability of VTE is higher in severe COVID-19 as compared with the general ICU patient.

In our meta-analysis, the fact that most included studies reported ongoing thromboprophylaxis at the time of VTE by using standard or even therapeutic doses of heparin further supports the hypothesis that SARS-CoV-2 itself may be an additional thrombotic stimulus, over and above traditional VTE risk factors. Accordingly, in the frame of subgroup 

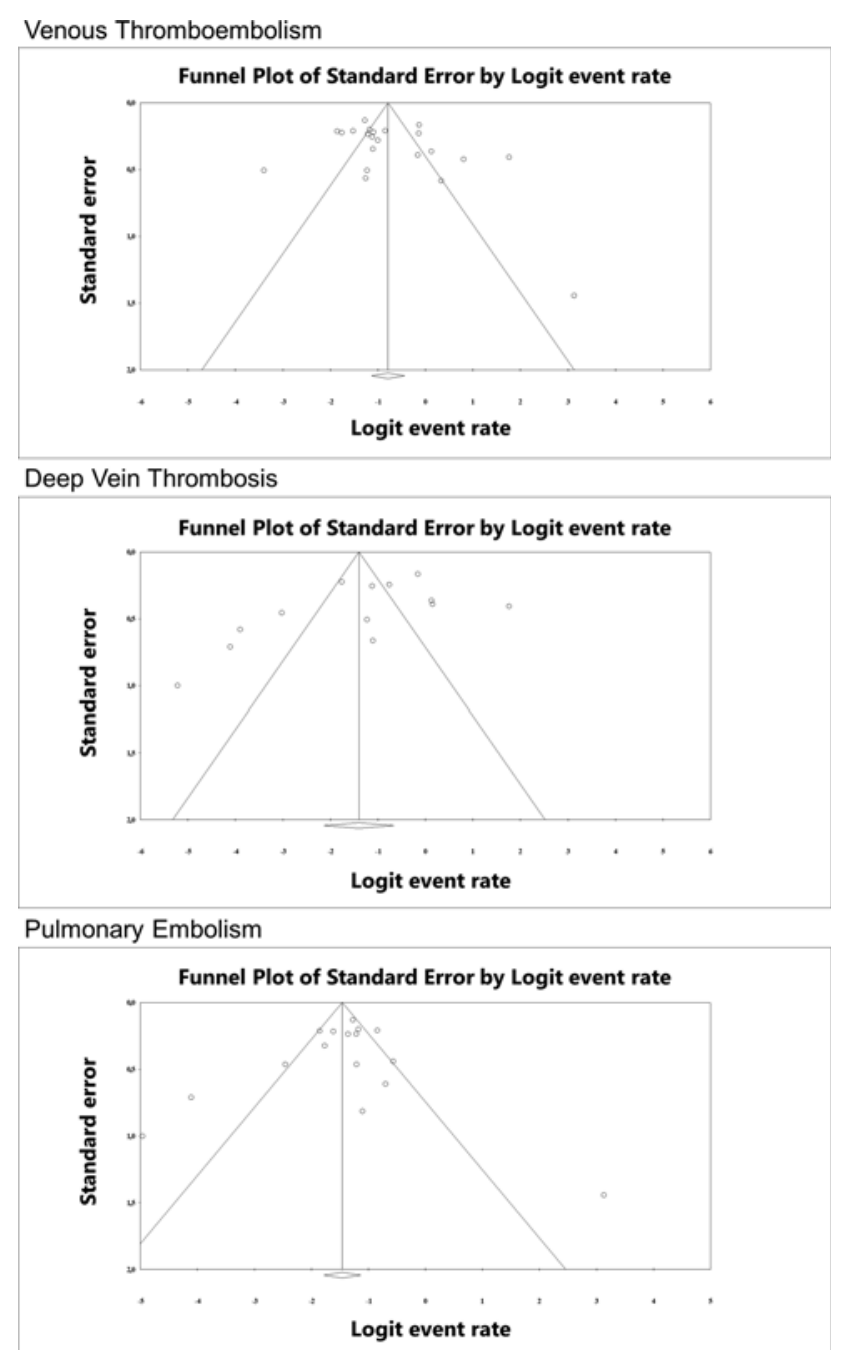

Fig. 3 Funnel plot of standard error by event rate of studies reporting on the prevalence of venous thromboembolism, deep vein thrombosis, and pulmonary embolism in COVID-19 patients.

analyses, we confirmed a high prevalence of VTE $(\approx 24 \%)$, DVT $(\approx 10 \%)$, and $\mathrm{PE}(\approx 15 \%)$ also when analyzing studies on patients receiving antithrombotic prophylaxis.

The thrombogenicity of COVID-19 has led some authors to wonder whether such an exceptionally high prevalence of thrombotic complications should be interpreted as a consequence of a localized thrombotic process in the lungs rather than an embolic phenomenon. ${ }^{40}$ In detail, it has been hypothesized that the inflammatory reaction in the lungs causes endothelial dysfunction, thus leading to the formation of pulmonary microthrombi. ${ }^{40}$ In keeping with this, the histological analysis of pulmonary vessels in patients with COVID-19 showed widespread thrombosis and microangiopathy, with alveolar capillary microthrombi being ninefold more prevalent in COVID-19 patients than in patients with H1N1 influenza. ${ }^{41}$ This may have relevant implications as the composition of pulmonary emboli and pulmonary microthrombi is different. In fact, while emboli reflect the composition of the distal part of the venous thrombi from which they originate, pulmonary microthrombi contain a large amount of platelets and fibrin. ${ }^{42}$ It is reasonable to assume
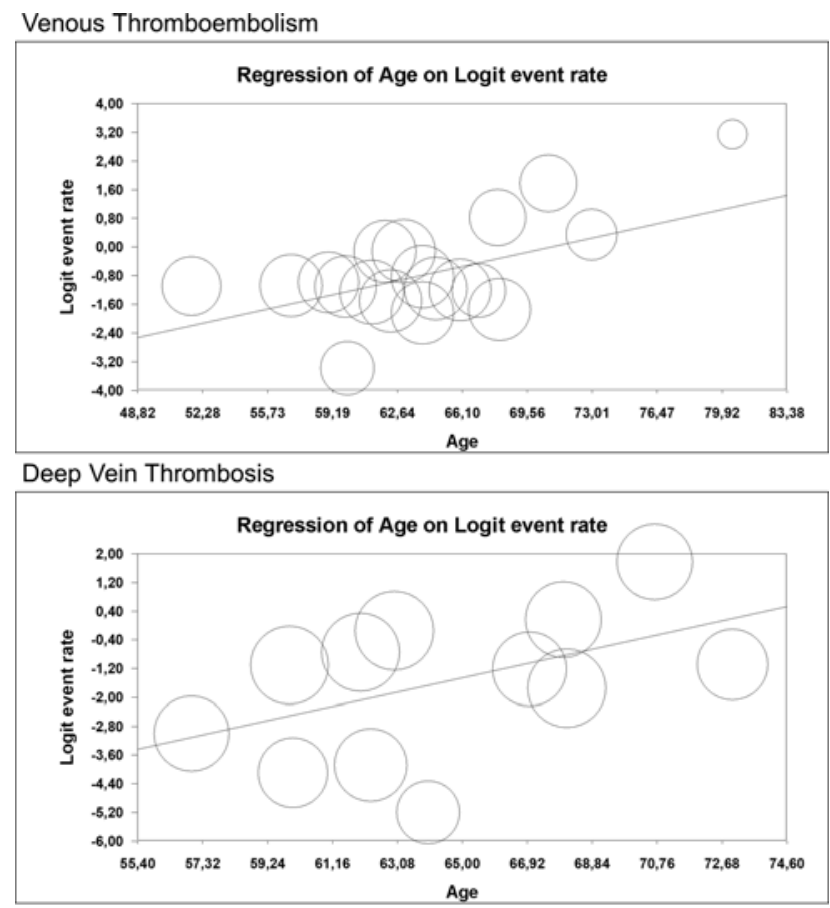

Pulmonary Embolism

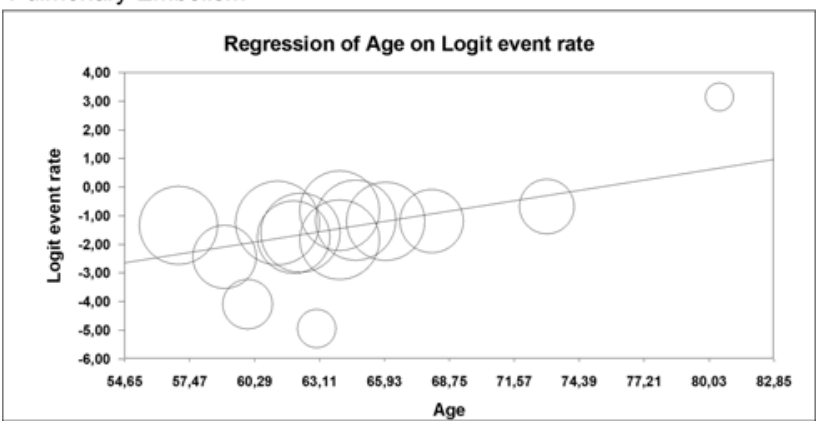

Fig. 4 Metaregression analysis. Impact of age on the prevalence of venous thromboembolism, deep vein thrombosis, and pulmonary embolism in COVID-19 patients.

that such different composition may significantly impact both therapeutic and prophylactic strategies. ${ }^{40}$

Taken together, the currently available data may suggest that SARS-CoV-2 infection can rapidly evolve into a severe condition with pulmonary and multiorgan involvement, potentially resulting in a consistent hemostatic imbalance. However, the mechanisms behind such hemostatic changes in severe patients with COVID-19 are still unclear.

Some previous articles focused on the association of COVID-19 severity with changes in primary and secondary hemostatic parameters, reporting that severe patients show longer prothrombin time (PT) and higher D-dimer values, with a lower platelet count. ${ }^{5,11,12,43-45}$ Similar results were found in nonsurvivors to COVID-19 as compared with survivors. Among 183 hospitalized patients with COVID-19, it has been documented that $71.4 \%$ of nonsurvivors have overt disseminated intravascular coagulation (DIC) as compared with only $0.6 \%$ of survivors. ${ }^{46,47}$ The presence of consumption coagulopathy among critically ill patients with SARS$\mathrm{CoV}-2$ infection may be in line with the observed changes in primary and secondary hemostatic parameters. The 
pathogenesis of DIC is complex and multifactorial, and the "cytokine storm" described in ICU patients with SARS-CoV-2 infection may somehow contribute to its development. ${ }^{48}$ However, many patients with severe COVID-19 may not fulfill the International Society on Thrombosis and Haemostasis (ISTH) criteria for DIC, ${ }^{49}$ as coagulopathy seems to have its peculiar features among these patients. For instance, thrombocytopenia is less pronounced in severe COVID-19 patients as compared with sepsis-related DIC, while D-dimer levels are particularly high. ${ }^{50}$ Moreover, although hyperfibrinogenemia is a common finding in COVID-19 patients, low fibrinogen levels have also been documented in nonsurvivors. ${ }^{48}$

Overall, based on available data, it can be hypothesized that the coagulopathy observed in severe COVID-19 may be a combination of a low-grade DIC with its own features and a localized pulmonary thrombotic microangiopathy. ${ }^{50}$

Considering the high thrombotic risk of COVID-19 patients, further specifically designed studies are needed to better address the issue of the hemostatic changes associated with COVID-19 severity. This could allow for a better understanding of the pathogenesis of this potentially fatal complication. Moreover, given the unknown long-term outcomes of COVID-19 and the increasing amount of literature data suggesting the presence of residual chronic disability and rehabilitation needs among survivors, ${ }^{51-57}$ it is compelling to identify new biomarkers related to the disease to timely predict its clinical progression and to adequately manage critical patients even after the acute phase (e.g., general ward, rehabilitation centers, and home). ${ }^{58}$

In the meantime, in all hospitalized COVID-19 patients, following the WHO and ISTH indications, ${ }^{59-61}$ prophylactic low-molecular-weight heparin (LMWH) or subcutaneous unfractionated heparin (UFH) should be considered.

Nevertheless, despite the lack of evidence supporting the prescription of high-dose prophylactic regimens, which may conversely increase the bleeding risk (particularly in patients with liver and renal impairment), the high rate of VTE reported during adequate thromboprophylaxis deserves to be considered and further investigated. ${ }^{62}$ The fact that some authors suggested the use of therapeutic doses in all hospitalized patients with COVID-19 even in the absence of randomized trial evidence ${ }^{25}$ reflects the belief in the medical community that standard thromboprophylaxis may be inadequate in the presence of such a strong prothrombotic switch.

Some potential limitations of our meta-analysis should be discussed. First, we have to consider that most included studies had a retrospective design and few studies $(n=5)$ enrolled consecutive COVID-19 patients undergoing imaging tests (Doppler ultrasound and/or computed tomography angiography) for VTE screening. Considering that symptoms of respiratory failure from COVID-19 are difficult to separate from those of $\mathrm{PE}$, the fact that most studies based the execution of imaging tests on signs and symptoms of VTE may contribute to the significantly high heterogeneity affecting our results. However, although we could not definitively establish sources of such heterogeneity, our findings were substantially confirmed by appropriate sensitivity and subgroup analyses. In particular, we extended our results analyzing studies systematically performing thrombosis screening in all enrolled patients, showing a fourfold increase in DVT diagnosis rate. This might support the hypothesis that a strict screening of thromboembolic complications in all COVID-19 patients is needed. Moreover, the impact of clinical and demographic variables on results was evaluated by means of meta-regression models. Finally, we excluded the presence of publication bias by using different methods.

\section{Conclusion}

Results of the present meta-analysis show that the rate of VTE in COVID-19 patients is not negligible and claims the attention on the need of adequate screening procedures and antithrombotic strategies to manage VTE. Failure of prevention and interventional strategies for the prothrombotic state of severe COVID-19 patients may dramatically impact their prognosis. While waiting for data from a larger number of studies, the high thromboembolic risk of COVID-19 patients should be considered to timely predict and manage the long-term outcomes of these patients with potentially disabling and fatal complications.

\section{Funding}

No financial support was received for this study.

\section{Conflict of Interest}

None.

\section{References}

1 Zhu N, Zhang D, Wang W, et al; China Novel Coronavirus Investigating and Research Team. A novel coronavirus from patients with pneumonia in China, 2019. N Engl J Med 2020;382(08):727-733

2 World Health Organization. Coronavirus disease 2019 (COVID19). Situation Report, 1. 2020. Available at: https://www.who.int/emergencies/diseases/novel-coronavirus-2019/situationreports. Accessed July 15, 2020

3 World Health Organization. Coronavirus disease 2019 (COVID19): Situation Report, 51. 2020. Available at: https://apps.who.int/iris/handle/10665/331475. Accessed July 15, 2020

4 Chan JF, Yuan S, Kok KH, et al. A familial cluster of pneumonia associated with the 2019 novel coronavirus indicating person-toperson transmission: a study of a family cluster. Lancet 2020;395 (10223):514-523

5 Guan WJ, Ni ZY, Hu Y, et al; China Medical Treatment Expert Group for COVID-19. Clinical characteristics of coronavirus disease 2019 in China. N Engl J Med 2020;382(18):1708-1720

6 Chen N, Zhou M, Dong X, et al. Epidemiological and clinical characteristics of 99 cases of 2019 novel coronavirus pneumonia in Wuhan, China: a descriptive study. Lancet 2020;395 (10223):507-513

7 Wan S, Xiang Y, Fang W, et al. Clinical features and treatment of COVID-19 patients in northeast Chongqing. J Med Virol 2020;92 (07):797-806

8 Wu P, Hao X, Lau EHY, et al. Real-time tentative assessment of the epidemiological characteristics of novel coronavirus infections in Wuhan, China, as at 22 January 2020. Euro Surveill 2020;25(03): 2000044

9 Solomon MZ, Wynia MK, Gostin LO. Covid-19 crisis triage optimizing health outcomes and disability rights. N Engl J Med 2020; Doi: 10.1056/NEJMp2008300 (epub ahead of print) 
10 Armitage R, Nellums LB. The COVID-19 response must be disability inclusive. Lancet Public Health 2020;5(05):e257

11 Mo P, Xing Y, Xiao Y, et al. Clinical characteristics of refractory COVID-19 pneumonia in Wuhan, China. Clin Infect Dis 2020; Doi: 10.1093/cid/ciaa270 (epub ahead of print)

$12 \mathrm{Wu} \mathrm{C}$, Chen X, Cai Y, et al. Risk factors associated with acute respiratory distress syndrome and death in patients with coronavirus disease 2019 pneumonia in Wuhan, China. JAMA Intern Med 2020; Doi: 10.1001/jamainternmed.2020.0994 (epub ahead of print)

13 Barbar S, Noventa F, Rossetto V, et al. A risk assessment model for the identification of hospitalized medical patients at risk for venous thromboembolism: the Padua Prediction Score. J Thromb Haemost 2010;8(11):2450-2457

14 Moher D, Liberati A, Tetzlaff J, Altman DG; PRISMA Group. Preferred reporting items for systematic reviews and meta-analyses: the PRISMA statement. BMJ 2009;339:b2535

15 Goldhaber SZ, Morrison RB. Cardiology patient pages. Pulmonary embolism and deep vein thrombosis. Circulation 2002;106(12): 1436-1438

16 Higgins JP, Thompson SG, Deeks JJ, Altman DG. Measuring inconsistency in meta-analyses. BMJ 2003;327(7414):557-560

17 Sterne JA, Egger M, Smith GD. Systematic reviews in health care: investigating and dealing with publication and other biases in meta-analysis. BMJ 2001;323(7304):101-105

18 Lodigiani C, Iapichino G, Carenzo L, et al; Humanitas COVID-19 Task Force. Venous and arterial thromboembolic complications in COVID-19 patients admitted to an academic hospital in Milan, Italy. Thromb Res 2020;191:9-14

19 Middeldorp S, Coppens M, van Haaps TF, et al. Incidence of venous thromboembolism in hospitalized patients with COVID-19. J Thromb Haemost 2020; Doi: 10.1111/jth.14888 (epub ahead of print)

20 Bompard F, Monnier H, Saab I, et al. Pulmonary embolism in patients with Covid-19 pneumonia. Eur Respir J 2020; Doi: 10.1183/13993003.01365-2020 (epub ahead of print)

21 Cui S, Chen S, Li X, Liu S, Wang F. Prevalence of venous thromboembolism in patients with severe novel coronavirus pneumonia. J Thromb Haemost 2020;18(06):1421-1424

22 Demelo-Rodríguez P, Cervilla-Muñoz E, Ordieres-Ortega L, et al. Incidence of asymptomatic deep vein thrombosis in patients with COVID-19 pneumonia and elevated D-dimer levels. Thromb Res 2020;192:23-26

23 Grillet F, Behr J, Calame P, Aubry S, Delabrousse E. Acute pulmonary embolism associated with COVID-19 pneumonia detected by pulmonary CT angiography. Radiology 2020; Doi: 10.1148/ radiol.2020201544 (epub ahead of print)

24 Helms J, Tacquard C, Severac F, et al; CRICS TRIGGERSEP Group (Clinical Research in Intensive Care and Sepsis Trial Group for Global Evaluation and Research in Sepsis). High risk of thrombosis in patients with severe SARS-CoV-2 infection: a multicenter prospective cohort study. Intensive Care Med 2020;46(06): 1089-1098

25 Klok FA, Kruip MJHA, van der Meer NJM, et al. Incidence of thrombotic complications in critically ill ICU patients with COVID-19. Thromb Res 2020;191:145-147

26 Lax SF, Skok K, Zechner P, et al. Pulmonary arterial thrombosis in COVID-19 with fatal outcome: results from a prospective, singlecenter, clinicopathologic case series. Ann Intern Med 2020; Doi: 10.7326/M20-2566 (epub ahead of print)

27 Leonard-Lorant I, Delabranche X, Severac F, et al. Acute pulmonary embolism in COVID-19 patients on CT angiography and relationship to D-dimer levels. Radiology 2020; Doi: 10.1148/ radiol.2020201561 (epub ahead of print)

28 Llitjos JF, Leclerc M, Chochois C, et al. High incidence of venous thromboembolic events in anticoagulated severe COVID-19 patients. J Thromb Haemost 2020;18(07):1743-1746
29 Marone EM, Rinaldi LF. Upsurge of deep venous thrombosis in patients affected by COVID-19: preliminary data and possible explanations. J Vasc Surg Venous Lymphat Disord 2020;8(04): 694-695

30 Poissy J, Goutay J, Caplan M, et al; Lille ICU Haemostasis COVID-19 Group. Pulmonary embolism in COVID-19 patients: awareness of an increased prevalence. Circulation 2020;142(02):184-186

31 Poyiadi N, Cormier P, Patel PY, et al. Acute pulmonary embolism and COVID-19. Radiology 2020; Doi: 10.1148/radiol.2020201955 (epub ahead of print)

32 Ren B, Yan F, Deng Z, et al. Extremely high incidence of lower extremity deep venous thrombosis in 48 patients with severe COVID-19 in Wuhan. Circulation 2020;142(02):181-183

33 Spiezia L, Boscolo A, Poletto F, et al. COVID-19-related severe hypercoagulability in patients admitted to intensive care unit for acute respiratory failure. Thromb Haemost 2020;120(06): 998-1000

34 Thomas W, Varley J, Johnston A, et al. Thrombotic complications of patients admitted to intensive care with COVID-19 at a teaching hospital in the United Kingdom. Thromb Res 2020;191:76-77

35 Wichmann D, Sperhake JP, Lütgehetmann M, et al. Autopsy findings and venous thromboembolism in patients with COVID19. Ann Intern Med 2020; Doi: 10.7326/M20-2003 (epub ahead of print)

36 Wright FL, Vogler TO, Moore EE, et al. Fibrinolysis shutdown correlation with thromboembolic events in severe COVID-19 infection. J Am Coll Surg 2020;231(02):193-203.e1

37 Zhang L, Feng X, Zhang D, et al. Deep vein thrombosis in hospitalized patients with coronavirus disease 2019 (COVID-19) in Wuhan, China: prevalence, risk factors, and outcome. Circulation 2020;142(02):114-128

38 Clayton TC, Gaskin M, Meade TW. Recent respiratory infection and risk of venous thromboembolism: case-control study through a general practice database. Int J Epidemiol 2011;40 (03):819-827

39 Malato A, Dentali F, Siragusa S, et al. The impact of deep vein thrombosis in critically ill patients: a meta-analysis of major clinical outcomes. Blood Transfus 2015;13(04):559-568

40 Thachil J, Srivastava A. SARS-2 coronavirus-associated hemostatic lung abnormality in COVID-19: Is it pulmonary thrombosis or pulmonary embolism? Semin Thromb Hemost 2020; Doi: 10.1055/s-0040-1712155 (epub ahead of print)

41 Ackermann M, Verleden SE, Kuehnel M, et al. Pulmonary vascular endothelialitis, thrombosis, and angiogenesis in Covid-19. N Engl J Med 2020;383(02):120-128

42 Chernysh IN, Nagaswami C, Kosolapova S, et al. The distinctive structure and composition of arterial and venous thrombi and pulmonary emboli. Sci Rep 2020;10(01):5112

43 Chen G, Wu D, Guo W, et al. Clinical and immunological features of severe and moderate coronavirus disease 2019. J Clin Invest 2020;130(05):2620-2629

44 Huang C, Wang Y, Li X, et al. Clinical features of patients infected with 2019 novel coronavirus in Wuhan, China. Lancet 2020;395 (10223):497-506

45 Xiong M, Liang X, Wei YD. Changes in blood coagulation in patients with severe coronavirus disease 2019 (COVID-19): a meta-analysis. Br J Haematol 2020;189(06):1050-1052

46 Yang X, Yu Y, Xu J, et al. Clinical course and outcomes of critically ill patients with SARS-CoV-2 pneumonia in Wuhan, China: a single-centered, retrospective, observational study. Lancet Respir Med 2020;8(05):475-481

47 Zhou F, Yu T, Du R, et al. Clinical course and risk factors for mortality of adult inpatients with COVID-19 in Wuhan, China: a retrospective cohort study. Lancet 2020;395(10229):1054-1062

48 Tang N, Li D, Wang X, Sun Z. Abnormal coagulation parameters are associated with poor prognosis in patients with novel coronavirus pneumonia. J Thromb Haemost 2020;18(04):844-847 
49 Taylor FB Jr, Toh CH, Hoots WK, Wada H, Levi M; Scientific Subcommittee on Disseminated Intravascular Coagulation (DIC) of the International Society on Thrombosis and Haemostasis (ISTH). Towards definition, clinical and laboratory criteria, and a scoring system for disseminated intravascular coagulation. Thromb Haemost 2001;86(05):1327-1330

50 Levi M, Thachil J, Iba T, Levy JH. Coagulation abnormalities and thrombosis in patients with COVID-19. Lancet Haematol 2020;7 (06):e438-e440

51 Babu AS, Vasanthan LT. Critical care rehabilitation - is it the answer for reducing morbidity in ARDS survivors? Regarding "Acute respiratory distress syndrome: a clinical review". Pulm Circ 2012;2(02):265

52 Borg K, Stam H. Editorial: Covid-19 and physical and rehabilitation medicine. J Rehabil Med 2020;52(04):jrm00045

53 Brugliera L, Spina A, Castellazzi P, et al. Rehabilitation of COVID-19 patients. J Rehabil Med 2020;52(04):jrm00046

54 Godeau E, Debeaumont D, Artaud-Macari E, Lagache L, Bouar GL, Coquart J. Sequelae of acute respiratory distress syndrome: interest of rehabilitation. Case Rep Crit Care 2019;2019:7953141

55 Herridge MS, Tansey CM, Matté A, et al; Canadian Critical Care Trials Group. Functional disability 5 years after acute respiratory distress syndrome. N Engl J Med 2011;364(14):1293-1304

56 Ambrosino P, Papa A, Maniscalco M, Di Minno MND. COVID-19 and functional disability: current insights and rehabilitation strategies. Postgrad Med J 2020; Doi: 10.1136/postgradmedj2020-138227 (epub ahead of print)

57 Simpson R, Robinson L. Rehabilitation after critical illness in people with COVID-19 Infection. Am J Phys Med Rehabil 2020; 99(06):470-474

58 Favaloro EJ, Lippi G. Recommendations for minimal laboratory testing panels in patients with COVID-19: potential for prognostic monitoring. Semin Thromb Hemost 2020;46:379-382

59 World Health Organization. Clinical management of severe acute respiratory infection when novel coronavirus (2019-nCoV) infection is suspected. Interim guidance 28 January 2020 . Available at: https://www.who.int/docs/defaultsource/coronaviruse/clinicalmanagement-of-novel-cov.pdf. Accessed July 15, 2020

60 Thachil J, Tang N, Gando S, et al. ISTH interim guidance on recognition and management of coagulopathy in COVID-19. J Thromb Haemost 2020;18(05):1023-1026

61 Bikdeli B, Madhavan MV, Jimenez D, et al; Global COVID-19 Thrombosis Collaborative Group, Endorsed by the ISTH, NATF, ESVM, and the IUA, Supported by the ESC Working Group on Pulmonary Circulation and Right Ventricular Function. COVID-19 and thrombotic or thromboembolic disease: implications for prevention, antithrombotic therapy, and follow-up: JACC stateof-the-art review. J Am Coll Cardiol 2020;75(23):2950-2973

62 Connors JM, Levy JH. COVID-19 and its implications for thrombosis and anticoagulation. Blood 2020;135(23):2033-2040 